\title{
Lacibacter cauensis gen. nov., sp. nov., a novel member of the phylum Bacteroidetes isolated from sediment of a eutrophic lake
}

Correspondence

Hong-Li Yuan

hlyuan@cau.edu.cn
Jian-Hang Qu, Hong-Li Yuan, Jin-Shui Yang, Hai-Feng Li and Nan Chen

State Key Lab for Agrobiotechnology, Key Laboratory of Agro-Microbial Resource and Application, Ministry of Agriculture, College of Biological Sciences, China Agricultural University, Beijing 100093, PR China

A novel strain, $\mathrm{NJ}-8^{\top}$, was isolated from sediment of the eutrophic Taihu Lake (China) and was subjected to a taxonomic study by using a polyphasic approach. The novel strain was aerobic and formed orange-pigmented colonies on R2A agar. Cells were Gram-negative single rods that were motile by means of gliding. Phylogenetic analysis based on 16S rRNA gene sequences showed that strain NJ-8 ${ }^{\top}$ belonged to the phylum Bacteroidetes, with Niastella yeongjuensis DSM $17621^{\top}$ (92.3\% gene sequence similarity) and Niastella koreensis DSM $17620^{\top}$ (92.0\% similarity) as its closest relatives. The major fatty acids ( $>5 \%$ of the total) were iso- $\mathrm{C}_{15: 0}(27.8 \%)$, iso- $_{15: 1} \mathrm{G}$ $(15.4 \%)$, iso- $\mathrm{C}_{17: 0} 3-\mathrm{OH}(14.5 \%)$ and summed feature 3 (comprising $\mathrm{C}_{16: 1} \omega 7 \mathrm{c}$ and/or iso$\left.\mathrm{C}_{15: 0} 2-\mathrm{OH} ; 13.9 \%\right)$. The genomic DNA G+C content was $46.6 \mathrm{~mol} \%$. Based on molecular and phenotypic data, strain $\mathrm{NJ}-8^{\top}$ is considered to represent a novel species of a new genus, for which the name Lacibacter cauensis gen. nov., sp. nov. is proposed. The type strain of the type species of the genus, Lacibacter cauensis, is $\mathrm{NJ}-8^{\top}\left(=\right.$ CGMCC $\left.1.7271^{\top}=\operatorname{NBRC} 104930^{\top}\right)$.
During the course of a study on the bacterial diversity in sediment from a eutrophic lake, a novel orange-pigmented bacterium, designated strain $\mathrm{NJ}-8^{\mathrm{T}}$, was isolated. On the basis of phylogenetic analysis, this strain was found to be most closely related to members of the genera Niastella, Terrimonas and Flavisolibacter, within the phylum Bacteroidetes. The genus Niastella was described by Weon et al. (2006) on the basis of two novel species, namely Niastella yeongjuensis and Niastella koreensis. Members of this genus are Gram-negative, aerobic, non-flagellated, gliding and filamentous micro-organisms. The genus Terrimonas was proposed by Xie \& Yokota (2006) with the description of Terrimonas lutea and the reclassification of [Flavobacterium] ferrugineum as Terrimonas ferruginea. The genus Terrimonas has recently been included in the family Crenotrichaceae along with the closely related genus Chitinophaga (Garrity et al., 2007). The genus Flavisolibacter was proposed by Yoon \& Im (2007) with the description of Flavisolibacter ginsengiterrae and Flavisolibacter ginsengisoli. In the present study, data from a polyphasic investigation show that strain $\mathrm{NJ}-8^{\mathrm{T}}$ represents a novel species of a new genus in the phylum

The GenBank/EMBL/DDBJ accession number for the 16S rRNA gene sequence of strain NJ-8 ${ }^{\top}$ is EU521690.

Maximum-parsimony and minimum-evolution phylogenetic trees based on 16S rRNA gene sequences are available with the online version of this paper.
Bacteroidetes related to, but distinct from, members of the genera Niastella, Terrimonas and Flavisolibacter.

Strain $\mathrm{NJ}-8^{\mathrm{T}}$ was isolated from the surface layer sediment of the highly eutrophic Taihu Lake in Jiangsu Province, China. This sediment was collected on 18 November 2007. For isolation, serially diluted sediment samples were spread onto plates of sediment steep medium prepared as follows: $400 \mathrm{~g}$ sediment was boiled in a litre of distilled water for $10 \mathrm{~min}$; $0.5 \mathrm{~g}$ peptone, $0.5 \mathrm{~g}$ yeast extract and $15 \mathrm{~g}$ agar were then added to a litre of supernatant (the $\mathrm{pH}$ was not adjusted). Plates were incubated at $28{ }^{\circ} \mathrm{C}$ for 7 days. A single colony of strain $\mathrm{NJ}-8^{\mathrm{T}}$ was picked and subcultured on modified R2A media (per litre distilled water: $0.5 \mathrm{~g}$ yeast extract, $0.5 \mathrm{~g}$ polypeptone, $0.5 \mathrm{~g}$ casein hydrolysate, $0.5 \mathrm{~g}$ glucose, $0.5 \mathrm{~g}$ soluble starch, $0.3 \mathrm{~g} \mathrm{~K} \mathrm{~K}_{2} \mathrm{HPO}_{4}$ and $0.05 \mathrm{~g} \mathrm{MgSO}_{4}$. $7 \mathrm{H}_{2} \mathrm{O} ; \mathrm{pH} 7.2$ ).

Cell morphology was observed under an Olympus light microscope at $\times 1000$ magnification with cells grown on R2A agar for 2 days at $28{ }^{\circ} \mathrm{C}$. Growth at 4, 20, 28, 37 and $50{ }^{\circ} \mathrm{C}$ and at pH 5, 5.5, 6.0, 6.5, 7.0, 7.5, 8.0 and 8.5 was assessed after 7 days incubation. The $\mathrm{pH}$ of the $\mathrm{R} 2 \mathrm{~A}$ broth was adjusted by adding $1 \mathrm{M} \mathrm{NaOH}$ or $1 \mathrm{M} \mathrm{HCl}$. Tolerance to salinity was tested in R2A broth supplemented with 0$5.0 \% \mathrm{NaCl}(\mathrm{w} / \mathrm{v})$ at $1 \%$ intervals after 7 days incubation. Growth on nutrient agar (NA), which was prepared in the laboratory according to the composition of Difco media, and LB agar (Sambrook \& Russell, 2001) was evaluated at $28{ }^{\circ} \mathrm{C}$ for 7 days. Flexirubin-type pigments were detected 
by flooding a small mass of bacterial cells with $20 \% \mathrm{KOH}$ according to the minimal standards described by Bernardet et al. (2002). Motility was investigated by using the hanging-drop technique with fresh cells in R2A broth. Utilization of carbon and energy sources was investigated in basal medium containing (per litre distilled water): $1 \mathrm{~g}$ $\left(\mathrm{NH}_{4}\right)_{2} \mathrm{SO}_{4}, 0.3 \mathrm{~g} \mathrm{~K}_{2} \mathrm{HPO}_{4}, 0.05 \mathrm{~g} \mathrm{MgSO}_{4} .7 \mathrm{H}_{2} \mathrm{O}$ and $0.1 \mathrm{~g}$ yeast extract $(\mathrm{pH} 7.2)$. Carbon substrates were added at a concentration of $0.5 \%(\mathrm{w} / \mathrm{v})$. After 7 days incubation, bromothymol blue $(0.1 \%, \mathrm{v} / \mathrm{v})$ was used as an indicator to test for the production of acids. Hydrolysis of starch $(0.2 \%, \mathrm{w} / \mathrm{v})$, casein $(1 \%, \mathrm{w} / \mathrm{v})$, pectin $(0.5 \%, \mathrm{w} / \mathrm{v})$, Tween $80(1 \%, \mathrm{v} / \mathrm{v})$, L-tyrosine $(0.5 \%, \mathrm{w} / \mathrm{v})$ and egg-yolk $(3 \%$, $\mathrm{v} / \mathrm{v}$ ) was tested by using R2A as the basal medium (Yi \& Chun, 2006). The Gram reaction, oxidase and catalase activities, methyl-red reaction, glucose oxidization/fermentation, nitrate reduction, denitrification, production of $\mathrm{H}_{2} \mathrm{~S}$, gelatin liquefaction, and lipase, lecithinase, $\beta$ galactosidase, urease, DNase and tryptophan deaminase activities were investigated according to the methods of Dong \& Cai (2001).

Cells grown in $\mathrm{R} 2 \mathrm{~A}$ broth for 2 days at $28{ }^{\circ} \mathrm{C}$ were used for cellular fatty acid analysis. Fatty acid methyl esters were prepared and identified by using the Sherlock Microbial Identification System (MIDI) according to the manufacturer's instructions. Genomic DNA was extracted accord- ing to Marmur (1961) from cells cultured for 2 days in R2A broth. The $\mathrm{G}+\mathrm{C}$ content of the DNA was determined by thermal denaturation (De Ley, 1970) by using DNA from Escherichia coli $\mathrm{K}-12$ as a control.

The phenotypic characteristics of strain $\mathrm{NJ}-8^{\mathrm{T}}$ are given in the genus and species descriptions below and in Table 1. The new isolate could be distinguished clearly from related taxa based on cell length, catalase activity and assimilation of carbohydrates.

PCR amplification of the $16 \mathrm{~S}$ rRNA gene was carried out by using the bacterial universal primers $27 \mathrm{~F}\left(5^{\prime}-\right.$ GAGAGTTTGATCCTGGCTCAG-3', E. coli position 2746) and 1495R (5'-CTACGGCTACCTTGTTACGA-3', E. coli position 1476-1495). A nearly complete sequence (1412 bp) was obtained with an ABI 3730 XL 96-capillary sequencer (Applied Biosystems). Identification of phylogenetic neighbours and calculation of pairwise $16 \mathrm{~S}$ rRNA gene sequence similarity were achieved by using the EzTaxon server (http://www.eztaxon.org/; Chun et al., 2007). Results showed that strain $\mathrm{NJ}-8^{\mathrm{T}}$ was most closely related to the type strains of $N$. yeongjuensis, $N$. koreensis, $T$. ferruginea, F. ginsengisoli, $F$. ginsengiterrae and T. lutea (92.3-90.8\% $16 \mathrm{~S}$ rRNA gene sequence similarity). Phylogenetic trees were constructed via MEGA, version 3.1 (Kumar et al., 2004), after multiple alignment of the data

Table 1. Differential phenotypic characteristics between strain $N J-8^{\top}$ and the type strains of related species

Strains: 1 , NJ-8 ${ }^{\mathrm{T}} ; 2$, N. yeongjuensis DSM $17621^{\mathrm{T}} ; 3$, N. koreensis DSM $17620^{\mathrm{T}} ; 4$, T. ferruginea IAM $15098^{\mathrm{T}} ; 5$, T. lutea IAM $15284^{\mathrm{T}} ; 6$, F. ginsengisoli Gsoil $643^{\mathrm{T}} ; 7$, F. ginsengiterrae Gsoil $492^{\mathrm{T}}$. Data for reference strains are from Weon et al. (2006), Kämpfer et al. (2006) and Yoon \& Im (2007).

+ , Positive; -, negative; $\mathrm{w}$, weakly positive; ND, not determined.

\begin{tabular}{|c|c|c|c|c|c|c|c|}
\hline Characteristic & 1 & 2 & 3 & 4 & 5 & 6 & 7 \\
\hline Cell length $(\mu \mathrm{m})$ & $1.0-2.0$ & $10-40$ & $10-50$ & $0.6-4.0$ & $1-2$ & $0.3-6.0$ & $0.3-1.0$ \\
\hline $\mathrm{H}_{2} \mathrm{~S}$ & + & $\mathrm{ND}$ & $\mathrm{ND}$ & - & - & - & - \\
\hline Oxidase & + & + & - & + & + & - & + \\
\hline Catalase & + & - & - & + & $\mathrm{w}$ & + & - \\
\hline Gliding motility & + & + & + & - & - & - & - \\
\hline Nitrate reduction & - & - & - & + & + & - & - \\
\hline Growth at $37{ }^{\circ} \mathrm{C}$ & + & - & + & + & + & + & - \\
\hline Highest $\mathrm{NaCl}$ tolerance $(\%)$ & 1.0 & ND & ND & 1.0 & 1.0 & 1.0 & 3.0 \\
\hline \multicolumn{8}{|l|}{ Hydrolysis of: } \\
\hline Carboxymethylcellulose & - & + & + & $\mathrm{ND}$ & $\mathrm{ND}$ & $\mathrm{ND}$ & ND \\
\hline Trehalose & + & $\mathrm{ND}$ & ND & - & + & $\mathrm{ND}$ & $\mathrm{ND}$ \\
\hline D-Xylose & - & $\mathrm{ND}$ & ND & + & - & $\mathrm{ND}$ & $\mathrm{ND}$ \\
\hline Melibiose & + & - & - & - & + & - & + \\
\hline Sucrose & + & - & - & - & + & + & + \\
\hline L-Rhamnose & + & - & - & + & - & - & + \\
\hline DNA G $+C$ content $(\mathrm{mol} \%)$ & 46.6 & 44.3 & 45.8 & 48.9 & 47.2 & 42.7 & 43.0 \\
\hline
\end{tabular}


by CLUSTAL $\mathrm{W}$ (Thompson et al., 1994). Three different algorithms (neighbour-joining, minimum-evolution and maximum-parsimony) were used and the topology of the tree was evaluated by using the Kimura two-parameter calculation model (Kumar et al., 2004) based on 1000 replicates. In the neighbour-joining tree (Fig. 1), strain $\mathrm{NJ}-8^{\mathrm{T}}, N$. yeongiuensis DSM $17621^{\mathrm{T}}, N$. koreensis DSM $17620^{\mathrm{T}}$, T. ferruginea IAM $15098^{\mathrm{T}}$, F. ginsengisoli Gsoil $643^{\mathrm{T}}, F$. ginsengiterrae Gsoil $492^{\mathrm{T}}$ and T. lutea IAM $15284^{\mathrm{T}}$ formed a single cluster. The minimum-evolution and maximum-parsimony trees showed essentially the same topology (see Supplementary Fig. S1 in IJSEM Online).

The major cellular fatty acids of strain $\mathrm{NJ}-8^{\mathrm{T}}$ were iso$\mathrm{C}_{15: 0}$, iso- $\mathrm{C}_{15: 1} \mathrm{G}$, iso- $\mathrm{C}_{17: 0} 3-\mathrm{OH}$ and summed feature 3 (comprising $\mathrm{C}_{16: 1} \omega 7 c$ and/or iso- $\mathrm{C}_{15: 0} 2-\mathrm{OH}$ ), a profile distinct from those of species of the genera Niastella and Terrimonas (Table 2).

The DNA G + C content of strain $\mathrm{NJ}-8^{\mathrm{T}}$ was $46.6 \mathrm{~mol} \%$, different from that of recognized species of the genera Niastella (44.3-45.8 mol\%; Weon et al., 2006) and Terrimonas (47.2-48.9 mol\%; Xie \& Yokota, 2006), as indicated in Table 1.

On the basis of phylogenetic and phenotypic data, strain $\mathrm{NJ}-8^{\mathrm{T}}$ is considered to represent a novel species of a new genus in the phylum Bacteroidetes, for which the name Lacibacter cauensis gen. nov., sp. nov. is proposed.

\section{Description of Lacibacter gen. nov.}

Lacibacter (La.ci.bac'ter. L. n. lacus lake; N.L. masc. n. bacter a rod; N.L. masc. n. Lacibacter rod-shaped bacterium from lake sediment).

Cells are aerobic, Gram-negative rods. Oxidase- and catalase-positive. Flexirubin-type pigments are absent. The major cellular fatty acids are iso- $\mathrm{C}_{15: 0}$, iso- $\mathrm{C}_{15: 1} \mathrm{G}$, iso- $\mathrm{C}_{17: 0} \quad 3-\mathrm{OH}$ and summed feature 3 (comprising $\mathrm{C}_{16: 1} \omega 7 c$ and/or iso- $\left.\mathrm{C}_{15: 0} 2-\mathrm{OH}\right)$. The type species is Lacibacter cauensis. Phylogenetically related to the genera Niastella, Terrimonas and Flavisolibacter in the phylum Bacteroidetes.

\section{Description of Lacibacter cauensis sp. nov.}

Lacibacter cauensis (cau.en'sis. N.L. masc. adj. cauensis pertaining to CAU, the acronym of the China Agricultural University, where the taxonomic studies on the type strain were performed).

Has the following characteristics in addition to those given in the genus description. Cells are single rods about 0.4$0.6 \mu \mathrm{m}$ in diameter and $1.0-2.0 \mu \mathrm{m}$ in length, and are motile by means of gliding. Colonies grown on R2A agar plates are circular, orange and about $0.5-1.0 \mathrm{~mm}$ in diameter after 7 days incubation at $28{ }^{\circ} \mathrm{C}$. Growth occurs at $20-37{ }^{\circ} \mathrm{C}$ (optimum, $28-37{ }^{\circ} \mathrm{C}$ ), at $\mathrm{pH} 5.5-8.0$ (optimum, $\mathrm{pH} 7.0$ ) and in the presence of $0-1 \% \mathrm{NaCl}$ (optimum, $0 \%$ ). Grows on NA (weakly) but not on LB agar. $\mathrm{H}_{2} \mathrm{~S}$ is produced. Negative for denitrification and reduction of nitrate. ONPG is hydrolysed. Methyl-red reaction is positive. Positive for hydrolysis of starch and casein. Negative reactions are observed for the hydrolysis of carboxymethylcellulose, pectin, Tween 80, urea and DNA. Tyrosine is weakly degraded, accompanied by production of a dark red pigment. Gelatin is liquefied slowly. Positive for oxidization of glucose and weakly positive for fermentation of glucose. Growth and acid formation occur with many carbohydrate substrates: maltose, sucrose, Dglucose, salicin, lactose, D-fructose, melezitose, D-galactose, raffinose, D-mannose, mannitol, L-rhamnose, trehalose, melibiose, myo-inositol, D-sorbitol and sodium succinate. Growth is strongest with maltose, sucrose and D-glucose. Unable to utilize D-xylose, D-sorbose, D-sodium gluconate, inulin, D-arabinose, L-arabinose, D-ribose, trisodium citrate dehydrate, L-asparagine, $n$-butanol or glycerol. Lecithinase and $\beta$-galactosidase are present but urease, tryptophan deaminase, DNase and lipase are absent. The major fatty acids are iso- $\mathrm{C}_{15: 0}$, iso- $\mathrm{C}_{15: 1} \mathrm{G}$, iso- $\mathrm{C}_{17: 0} 3-\mathrm{OH}$ and summed feature 3 (comprising $\mathrm{C}_{16: 1} \omega 7 c$ and/or iso- $\mathrm{C}_{15: 0}$ $2-\mathrm{OH})$.

The type strain, NJ-8 $8^{\mathrm{T}} \quad\left(=\mathrm{CGMCC} \quad 1.7271^{\mathrm{T}}=\mathrm{NBRC}\right.$ $104930^{\mathrm{T}}$ ), was isolated from the sediment of Taihu Lake in Jiangsu Province, China. The $\mathrm{G}+\mathrm{C}$ content of the genomic DNA of the type strain is $46.6 \mathrm{~mol} \%$.

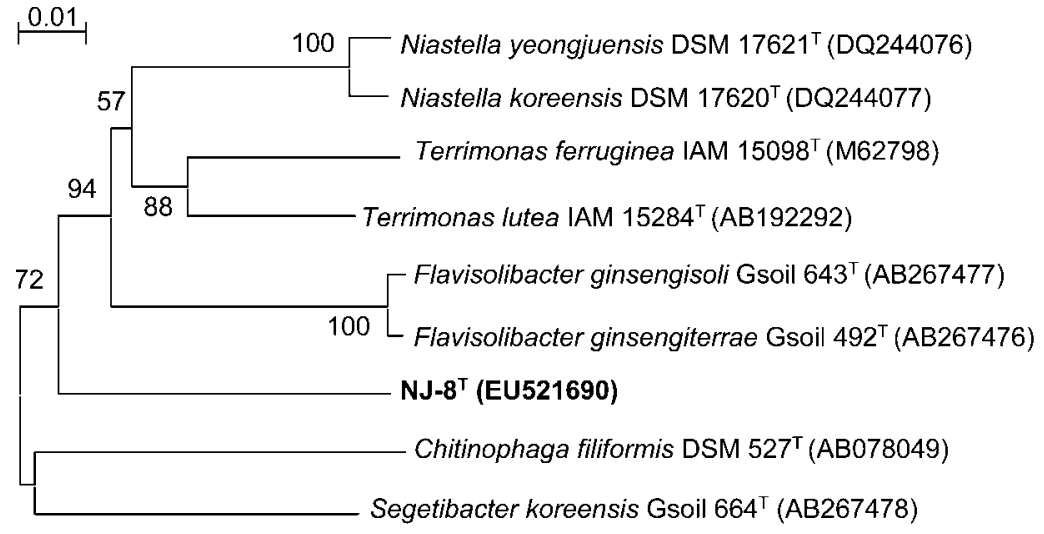

http://ijs.sgmjournals.org
Fig. 1. Neighbour-joining phylogenetic tree based on 16S rRNA gene sequences showing the position of strain $\mathrm{NJ}-8^{\top}$ among related species. Numbers at nodes indicate bootstrap percentages (based on 1000 replicates); only values $>50 \%$ are shown. Bar, 0.01 substitutions per nucleotide position. 
Table 2. Cellular fatty acid composition (\%) of strain $\mathrm{NJ}-8^{\top}$ and related species

Strains: 1 , NJ-8 $8^{\mathrm{T}} ; 2$, N. yeongjuensis DSM $17621^{\mathrm{T}} ; 3$, N. koreensis DSM $17620^{\mathrm{T}} ; 4$, T. ferruginea IAM $15098^{\mathrm{T}} ; 5$, T. lutea IAM $15284^{\mathrm{T}} ; 6$, F. ginsengisoli Gsoil $643^{\mathrm{T}} ; 7$, F. ginsengiterrae Gsoil $492^{\mathrm{T}}$. Data for reference strains are from Weon et al. (2006), Kämpfer et al. (2006) and Yoon \& Im (2007). Fatty acids amounting to $<1 \%$ of the total fatty acids in all strains studied are not listed. tr, trace $(<1 \%)$.

\begin{tabular}{|c|c|c|c|c|c|c|c|}
\hline Fatty acid & 1 & 2 & 3 & 4 & 5 & 6 & 7 \\
\hline Unknown 13.565 & 4.2 & & & 1.3 & 3.2 & & \\
\hline iso- $\mathrm{C}_{14: 0}$ & $\operatorname{tr}$ & & & 1.1 & 4.3 & & \\
\hline iso- $\mathrm{C}_{15: 1} \mathrm{G}$ & 15.4 & 14.7 & 15.6 & & & & \\
\hline iso- $\mathrm{C}_{15: 1}$ & & & & 26.2 & 21.8 & 4.4 & 5.3 \\
\hline iso- $\mathrm{C}_{15: 0}$ & 27.8 & 30.6 & 26.8 & 28.4 & 34.8 & 31.2 & 45.9 \\
\hline anteiso- $\mathrm{C}_{15: 0}$ & $\operatorname{tr}$ & 3.3 & 4.9 & $\operatorname{tr}$ & & 5.0 & 5.9 \\
\hline $\mathrm{C}_{15: 0}$ & 4.7 & & & 2.7 & $\operatorname{tr}$ & & \\
\hline iso- $\mathrm{C}_{16: 0}$ & $\operatorname{tr}$ & & 1.0 & 1.4 & & & \\
\hline $\mathrm{C}_{16: 1} \omega 5 c$ & 1.6 & 1.2 & & & & & \\
\hline$C_{16: 0}$ & 2.4 & 2.9 & 2.6 & 1.7 & 1.1 & 7.5 & 5.5 \\
\hline iso- $\mathrm{C}_{15: 0} 3-\mathrm{OH}$ & 2.7 & 1.9 & 1.3 & 2.2 & 2.3 & 1.0 & 1.4 \\
\hline Unknown 16.582 & 1.5 & 1.6 & 1.4 & 1.3 & 1.8 & & \\
\hline iso- $\mathrm{C}_{17: 0}$ & 1.2 & & 1.6 & & & 9.1 & 3.1 \\
\hline anteiso- $\mathrm{C}_{17: 0}$ & & & & & & 1.0 & \\
\hline iso- $\mathrm{C}_{17: 1} \omega 9 c$ & & & & & & & 1.3 \\
\hline$C_{16: 0}$ 10-methyl & & & & & & 2.6 & \\
\hline $\mathrm{C}_{16: 0} 2-\mathrm{OH}$ & & & & & & 2.9 & \\
\hline $\mathrm{C}_{16: 0} 3-\mathrm{OH}$ & $\operatorname{tr}$ & 2.3 & 1.3 & 2.5 & 3.3 & & \\
\hline $\mathrm{C}_{18: 1} \omega 7 c$ & 1.9 & & & & & & \\
\hline $\mathrm{C}_{18: 0}$ & $\operatorname{tr}$ & & & & & 2.0 & \\
\hline iso- $\mathrm{C}_{17: 0} 3-\mathrm{OH}$ & 14.5 & 27.1 & 29.4 & 15.3 & 14.2 & 11.8 & 13.7 \\
\hline $\mathrm{C}_{17: 0} 2-\mathrm{OH}$ & & 2.6 & 3.5 & & & & \\
\hline $\mathrm{C}_{17: 0} 3-\mathrm{OH}$ & $\operatorname{tr}$ & & 1.2 & & & & \\
\hline \multicolumn{8}{|l|}{ Summed feature:* } \\
\hline 2 & & & & & & 2.5 & 2.7 \\
\hline 3 & 13.9 & 5.3 & 4.3 & 11.2 & 14.9 & & \\
\hline 4 & 1.2 & & & & & 6.2 & 10.5 \\
\hline 5 & & & & & & 3.1 & 1.4 \\
\hline 6 & & & & & & 1.7 & \\
\hline 7 & & & & & & 1.2 & \\
\hline
\end{tabular}

${ }^{*}$ Summed features are combinations of fatty acids that cannot be separated by the MIDI system. Summed feature 2 comprises $\mathrm{C}_{12: 0}$ aldehyde, $\mathrm{C}_{14: 0} 3-\mathrm{OH}$ and/or iso- $\mathrm{C}_{16: 1}$; summed feature 3 comprises $\mathrm{C}_{16: 1} \omega 7 \mathrm{c}$ and/or iso- $\mathrm{C}_{15: 0}$ 2-OH; summed feature 4 comprises iso- $\mathrm{C}_{17: 1} \mathrm{I}$ and/or anteiso- $\mathrm{C}_{17: 1} \mathrm{~B}$; summed feature 5 comprises iso- $\mathrm{C}_{17: 1} \mathrm{I}$ and/or anteiso$\mathrm{C}_{17: 1} \mathrm{~B}$; summed feature 6 comprises $\mathrm{C}_{18: 2} \omega 6,9 c$ and/or anteiso- $\mathrm{C}_{18: 0}$; and summed feature 7 comprises $\mathrm{C}_{18: 1} \omega 7 c$, $\mathrm{C}_{18: 1} \omega 9 t$ or $\mathrm{C}_{18: 1} \omega 12 t$ or any combination of these isomers.

\section{Acknowledgements}

This work was supported by the Taihu Project (No. BK2007741) from Jiangsu Science and Technology Department, a project from the Chinese National Natural Science Foundation (No. 30670071) and the China Postdoctoral Science Foundation (No. 20070420432).

\section{References}

Bernardet, J. F., Nakagawa, Y. \& Holmes, B. (2002). Proposed minimal standards for describing new taxa of the family Flavobacteriaceae and emended description of the family. Int J Syst Evol Microbiol 52, 1049-1070.
Chun, J., Lee, J.-H., Jung, Y., Kim, M., Kim, S., Kim, B. K. \& Lim, Y. W. (2007). EzTaxon: a web-based tool for the identification of prokaryotes based on 16S ribosomal RNA gene sequences. Int J Syst Evol Microbiol 57, 2259-2261.

De Ley, J. (1970). Reexamination of the association between melting point, buoyant density, and chemical base composition of deoxyribonucleic acid. J Bacteriol 101, 738-754.

Dong, X.-Z. \& Cai, M.-Y. (2001). Determinative Manual for Routine Bacteriology. Beijing: Scientific Press.

Garrity, G., Lilburn, T., Cole, J., Harrison, S., Euzéby, J. \& Tindall, B. (2007). Part 11 - The Bacteria: Phyla 'Planctomycetes', 'Chlamydiae', 'Spirochaetes', 'Fibrobacteres', 'Acidobacteria', 'Bacteroidetes', 'Fusobacteria', 'Verrucomicrobia', 'Dictyoglomi', 'Gemmatomonadetes', 
and 'Lentisphaerae'. In The Taxonomic Outline of Bacteria and Archaea, TOBA release 7.7. doi: 10.1601/toba.v7i7.188

Kämpfer, P., Young, C. C., Sridhar, K. R., Arun, A. B., Lai, W. A., Shen, F. T. \& Rekha, P. D. (2006). Transfer of [Flexibacter] sancti, [Flexibacter] filiformis, [Flexibacter] japonensis, and [Cytophaga] arvensicola to the genus Chitinophaga and description of Chitinophaga skermanii sp. nov. Int J Syst Evol Microbiol 56, 2223-2228.

Kumar, S., Tamura, K. \& Nei, M. (2004). MEGA3: integrated software for molecular evolutionary genetics analysis and sequence alignment. Brief Bioinform 5, 150-163.

Marmur, J. (1961). A procedure for the isolation of deoxyribonucleic acid from microorganisms. J Mol Biol 3, 208-218.

Sambrook, J. \& Russell, D. W. (2001). Molecular Cloning, a Laboratory Manual, 3rd edn. Cold Spring Harbor, NY: Cold Spring Harbor Laboratory.

Thompson, J. D., Higgins, D. G. \& Gibson, T. J. (1994). CLUSTAL W: improving the sensitivity of progressive multiple sequence alignment through sequence weighting, position-specific gap penalties and weight matrix choice. Nucleic Acids Res 22, 4673-4680.

Weon, H.-Y., Kim, B.-Y., Yoo, S.-H., Lee, S.-Y., Kwon, S.-W., Go, S.-J. \& Stackebrandt, E. (2006). Niastella koreensis gen. nov., sp. nov. and Niastella yeongjuensis sp. nov., novel members of the phylum Bacteroidetes, isolated from soil cultivated with Korean ginseng. Int J Syst Evol Microbiol 56, 1777-1782.

Xie, C.-H. \& Yokota, A. (2006). Reclassification of [Flavobacterium] ferrugineum as Terrimonas ferruginea gen. nov., comb. nov., and description of Terrimonas lutea sp. nov., isolated from soil. Int J Syst Evol Microbiol 56, 1117-1121.

Yi, H. \& Chun, J. (2006). Flavobacterium weaverense sp. nov. and Flavobacterium segetis sp. nov., novel psychrophiles isolated from the Antarctic. Int J Syst Evol Microbiol 56, 1239-1244.

Yoon, M.-H. \& Im, W.-T. (2007). Flavisolibacter ginsengiterrae gen. nov., sp. nov. and Flavisolibacter ginsengisoli sp. nov., isolated from ginseng cultivating soil. Int J Syst Evol Microbiol 57, 18341839. 